\title{
An X-ray CT study of miniature clay sample preparation techniques
}

\author{
Christopher Ibeh ${ }^{1, *}$, Matteo Pedrotti ${ }^{1}$, Alessandro Tarantino ${ }^{1}$, and Rebecca Lunn $^{1}$ \\ ${ }^{1}$ University of Strathclyde, Department of Civil and Environmental Engineering, G1 1XJ, United Kingdom
}

\begin{abstract}
The quality and reliability of cohesive soil laboratory test data can be significantly affected by sample disturbance during sampling or sample preparation. Sample disturbance may affect key design and modelling parameters such as stiffness, preconsolidation stress, compressibility and undrained shear strength, and ultimately determine particle mobilization and shear plane development. The use of X-ray computed tomography (X-CT) in the study of soil is restricted by the inverse relationship of specimen size and obtainable image resolution. This has led to the testing of miniature specimen sizes which are far less than conventional laboratory sample size in a bid to obtain high resolution images and detailed particle-scale soil properties; however, these miniature soil specimens are more prone to sample disturbance. In this work $2 \%$ muscovite was mixed with speswhite kaolin clay as a strain marker for use in X-CT. The clay soil sample was prepared from slurry and either consolidated using an oedometer or a gypsum mould. Specimens obtained from a $7 \mathrm{~mm}$ tube sampler were compared to lathe trimmed specimens with a diameter (Ø) of $7 \mathrm{~mm}$. Results from X-CT imaging were used to study the influence of sampler type on specimen disturbance, by analysing the muscovite particle orientation of the obtained 3D images. The results show that; for samples subjected to large consolidation stress $(>200 \mathrm{kpa})$ lathe trimmed specimens may be subject to lesser disturbance compared to tube sampled specimens.
\end{abstract}

\section{Introduction}

Laboratory specimen quality is important to obtain reliable and representative soil parameters, however, a great deal of disturbance to the soil specimen may occur during sampling. If the soil specimen loses its original structure, the test-derived soil parameters may be unrepresentative and lead to overly conservative designs [1]. Similarly, soil modelling requires input parameters to be as close as possible to the actual experiment data, hence significant sample disturbance should be avoided.

With the proliferation of X-ray Computed Tomography (X-CT) in soil mechanics, there is currently no standard guide for the preparation of miniature soil specimens for X-CT and there are no specifications for approaches to the preparation of these miniature specimens. Miniature specimens are obtained from largescale samples prepared with conventional methods, -for example, from a conventional triaxial sample that is $38 \mathrm{~mm}$ by $72 \mathrm{~mm}$ - The deformation of a soil is affected by its initial state, and if a specimen has undergone significant deformation ab initio, this may well determine how the sample further deforms. Currently, the testing miniature soil specimens under the X-CT has focused on observing phenomena without really considering the effects of sample preparation and the degree of specimen disturbance. These latter considerations raise a number of questions such as: Is the specimen being tested representative of the original sample? Does the sample preparation approach lead to significant initial sample deformation that affects how particles ultimately behave? How much specimen disturbance does the sampling approach, such as tube sampling or lathe-trimmed block sampling cause to miniature specimens and are these disturbances within acceptable limits for a representative soil?

Traditionally, it is considered adequate to take samples which have a minimum dimension of the order of 5-10 times the maximum particle size of the soil. [2] suggests that sample sizes should be determined on the basis both of the soil type and the purpose for which the sample is needed. Additional, -research has shown that sample disturbance may affect estimates of shear strength on soft clays and soil may be so disturbed as to contain zones of potential weakness along which slippage may occur during strength testing, hence the level of disturbance to which the soil is subjected should be acceptable [3].

\footnotetext{
* Corresponding author: Christopher.ibeh@strath.ac.uk
} 


\subsection{Miniature soil sample preparation techniques}

In the laboratory, remoulded miniature specimens can be produced by cutting blocks of soil and then trimming it to the desired shape using a soil lathe, by pushing or driving tubes into a larger sample (see figure 1a below) or by preparing a soil specimen just to size either using a gypsum mould (see figure $1 \mathrm{~b}$ below) or a miniature oedometer. Each of these specimen preparation approaches may impose a certain degree of disturbance on the resulting soil specimen.

Trimmed block sampling is recommended, as it is considered of a better-quality over piston/tube derived samples in conventional geomechanics soil sampling [1], [4]. What constitutes an "undisturbed sample" is unknown, as no definitive method exists to obtain a "perfect sample" let alone "a perfect unconventional miniature soil specimen". Therefore, there is the need to assign a confidence level to sample quality assessment [5].
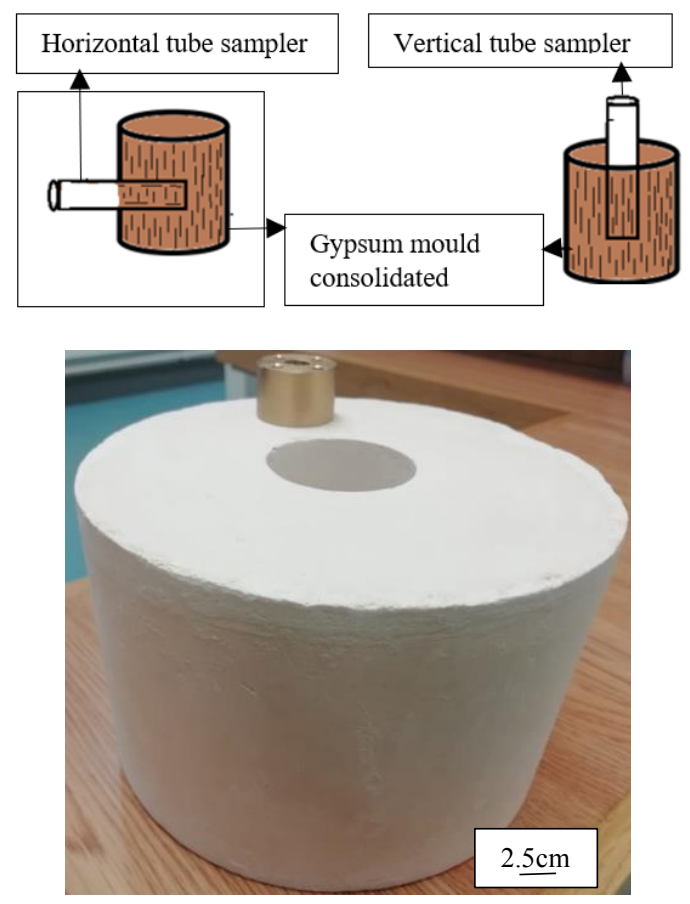

Fig. 1a: Tube sampling configuration (not to scale); b) large Cylindrical hollow gypsum mould for consolidating clay sample

The aim of this study is to determine and compare the degree of miniature specimen disturbance imposed by different sampling approaches. We used mica particles (fine silt to sand sized) as remoulded clay specimen strain markers. This is because, X-ray CT resolution is in the order of a few microns, but clay particles are less than 2 microns in size. Particle orientation analysis using stereographic projections and Fisher statistics were used to determine the amount of specimen disturbance. A specially prepared gypsum mould and a conventional oedometer were used to prepare samples with different particle configuration; these were then subsampled using a tube and a lathe.

\section{Material}

Slurries were prepared using speswhite kaolin purchased from IMERYS Minerals Limited (with a liquid limit of 63 and a particle size range of 0.3 micron to 6 microns and an average particle size of 0.7 microns) and sand muscovite mica from LKAB minerals LTD (the mica was crushed to a range of particle size between 10 microns and 200 microns and an average size of 90 micron). A firm plastic tube sampler with an inner diameter of $7 \mathrm{~mm}$, a metal soil lathe and a specially produced hollow cylindrical gypsum mould were used to prepare the specimens. A mould with inner and outer diameters of $38 \mathrm{~mm} 120 \mathrm{~mm}$ was used. The gypsum mould was prepared using conventional ceramic gypsum mould preparation approach.

\section{Sample Preparation}

Two different consolidation methods were adopted: suction induced consolidation using a large gypsum mould, and conventional oedometer consolidation. For the mould sample, after mixing the appropriate amount of kaolin and mica (2\% wt mica) with de-aired distilled water (using 4 times the liquid limit of kaolin $-252 \%$ ), a shear- mixer was used to homogenize the slurry for 30 min. Thereafter, the slurry is consolidated with either of the larger sized or the smaller sized gypsum mould, by pouring the slurry into the mould at intervals (ensuring no space in the mould as it consolidated) until a firm sample is cast (total of about $2 \mathrm{hrs}$ for the $38 \mathrm{~mm}$ sample and about 20 minutes for the $7 \mathrm{~mm}$ sample). After consolidation (to $100 \mathrm{kpa}$ ), the mould is then lifted leaving behind the sample. The oedometer sample was prepared using 1.5 times the liquid limit of kaolin (96\%), consolidated to $2200 \mathrm{kpa}$, unloaded to $200 \mathrm{kpa}$ and quickly drained (overconsolidated specimen).

Specimens were either sampled using a miniature tube sampler or, a soil lathe. A total of four specimen types were studied (see table 1 below):

i) a vertical tube specimen derived by inserting the tube sampler vertically through the sample consolidated in the large cylindrical gypsum mould (LM-VT),

ii) a horizontally tube specimen derived by inserting the tube sampler horizontally across the sample consolidated in the large cylindrical gypsum mould (LM-HT),

iii) a vertical tube specimen derived by inserting the tube sampler vertically through the overconsolidated oedometer sample (OED-VT), and

iv) a lathe trimmed vertical specimen derived from the oedometer consolidated sample (OED-VL) and

After preparing the lathe trimmed and mould specimens, the specimens were covered with liquid latex to prevent moisture loss during imaging. The tube derived specimens were imaged without extrusion from the tubes so as to have the least possible tube disturbance; the top and bottom of the tubes were sealed with liquid latex before imaging. 


\section{Methodology}

In this study, because of the miniature specimen size, we have restricted the evaluation approach to non-destructive testing, specifically the use of X-CT (with mica as a strain marker). Particle orientation at the specimen's outer surface (surface thickness defined as 2 times the average marker particle length) was compared to the internal particle orientation of the specimen, see figure 2 below.

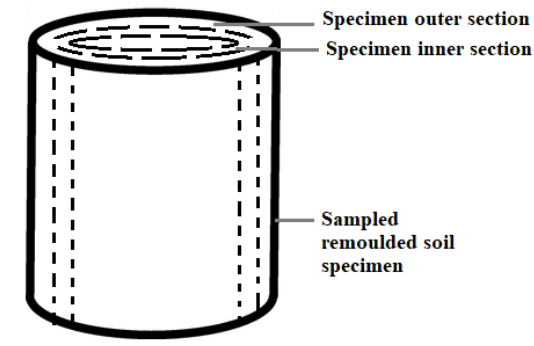

Fig. 2: Typical specimen sections analysed for disturbance (not to scale)

\subsection{X-CT imaging}

X-ray CT imaging of the samples were performed by means of a Nikon XT H 320 X-Ray CT scanner (at the University of Strathclyde, advanced materials laboratory) In the present work, the voxel resolution was approximately $5 \mu \mathrm{m}$ and the scanner settings were energy $150 \mathrm{kV}$ and current $38 \mu \mathrm{A}$.

Table 1: description and schematic of specimens studied

\begin{tabular}{lllll}
\hline $\begin{array}{l}\text { Sample } \\
\text { consolidation } \\
\text { method }\end{array}$ & $\begin{array}{l}\text { Lathe } \\
\text { trimmed } \\
\text { block } \\
\text { sample }\end{array}$ & $\begin{array}{l}\text { Vertical } \\
\text { Tube } \\
\text { sample }\end{array}$ & $\begin{array}{l}\text { Horizon } \\
\text {-tal Tube } \\
\text { sample }\end{array}$ & $\begin{array}{l}\text { Speci- } \\
\text { men } \\
\text { prepar } \\
\text { ed to } \\
\text { size }\end{array}$ \\
\hline $\begin{array}{l}\text { Oedometer } \\
\text { Consolidated }\end{array}$ & & &
\end{tabular}

The reconstruction was carried out using CT Pro and CT Agent software (Nikon189 Metrology). The visualization and analysis of the CT data was performed with AVIZO 9.0 [6]. Avizo border kill tool was used to remove all particles touching the sampler border and the particle long-axis orientations were exported to the Stereonet software [7-9] for particle distribution and orientation analysis.

\subsection{Stereographic projection}

Contoured stereoplots were used for the presentation and analysis of the mica particle orientations, enabling 3- dimensional data to be plotted in two dimensions. The stereonets were plotted using the Stereonet software with the orientation of the mica particles plotted as poles to the planes.

\subsection{Spatial statistical analysis (Fisher Spherical distribution}

The Fisher distribution is the basic model for directions distributed unimodally with rotational symmetry and it is the direct generalization for a sphere of the von Misses distribution on the circle [10]. According to [9] the distribution is the standard mean vector calculation such that the direction cosines of all the individual unit vectors are simply added up; the mean length is the length of the resultant vector divided by the number of vectors summed and the reported trend is derived from the resultant vector normalized to a unit vector.

The shape parameter k (or kappa) also known as the dispersion or the concentration factor, is estimated from equation (1):

$$
k \approx(\mathrm{N}-1) /(\mathrm{N}-\mathrm{R}) \text { for } \mathrm{N} \geq 16
$$

The uncertainty intervals are calculated from the equation (2) below:

$$
\cos \delta \alpha=1-\left(\frac{N-R}{R}\right)\left[\left(\frac{1}{1-P}\right)^{\frac{1}{N-1}}-1\right]
$$

where $\mathrm{N}$ is the number of observations, $\mathrm{P}$ is the probability, and $\mathrm{R}$ is the resultant vector length. The larger the value of $\mathrm{k}$, the more the distribution is concentrated towards the equivalent direction cosines.

The hypothesis tested is that the inner specimen particles are distributed more directionally to the mean whole sample direction than the outer specimen particles, that is, that the absolute difference of the $\mathrm{k}$ between the specimen outer section and the inner section is smaller for a less disturbed specimen than for a more disturbed specimen. This is expected to be the case if the outer part of the specimen is significantly disturbed in a direction away from the mean specimen direction.

With $\Delta \mathrm{k}=$ absolute difference between the inner and outer section $\mathrm{k}$ values

$$
\begin{aligned}
& \mathrm{H}_{0}:\left(|\Delta \mathrm{k}|_{\text {less disturbed specimen }}\right)>\left(|\Delta \mathrm{k}|_{\text {more disturbed specimen }}\right) \\
& \mathrm{H}_{1}:\left(|\Delta \mathrm{k}|_{\text {less disturbed specimen }}\right)<\left(|\Delta \mathrm{k}|_{\text {more disturbed specimen }}\right)
\end{aligned}
$$

For each of the specimens, 1000 of the larger mica particles in the inner specimen section and 1000 mica particles in the outer specimen section (also the larger particles) were each analysed for the section's concertation factor $\mathrm{k}$. This was done using an equal area stereographic projection and the Fisher statistics distribution. The larger mica particles were used because of the limitations imposed by the X-CT resolution. 


\section{Results and Discussion}

\subsection{Tube and lathe derived Oedometer overconsolidated specimens}

Results of the Fisher spherical distribution analysis of the stereplots for all of the specimen types tested are presented in figure 3 below. For the OED -VT, the inner section particles are aligned more closely to the horizontal, as compared to the particles at the outer section which are oriented vertically (due to the tube sampler effect - see figure $5 \mathrm{c}$ below) and horizontally. In the case of, - the, OED -VL, there are also more vertically oriented particles in the outer section, but the effect is not as in the OED-VT.

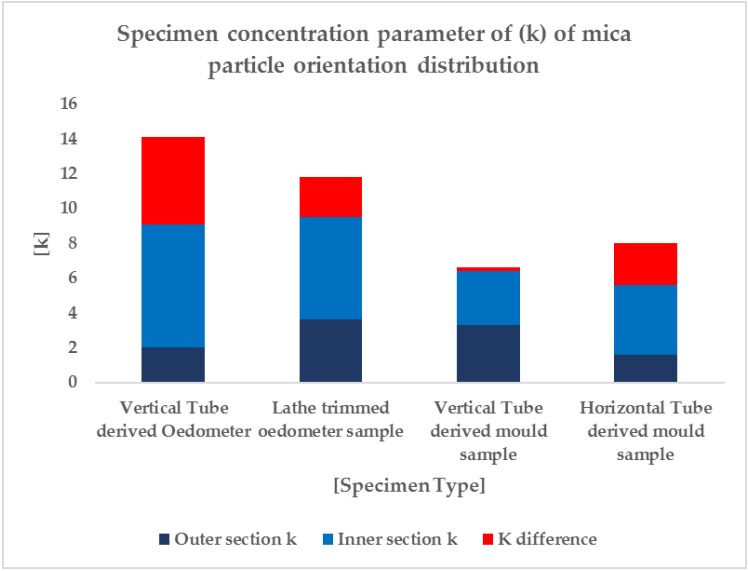

Fig. 3: concentration parameter of mica particle orientation distribution (N-1000; 95\% significance)

The k-values for the vertical tube sampled oedometer overconsolidated specimen are 2.1 (outermost section) and 7.1 (inner section) and the difference is 5.0 all at 95\% confidence level, while for the lathe trimmed oedometer overconsolidated specimen, the $\mathrm{k}$ value for the outer section is 3.6, as compared to 5.9 for the inner section and a difference of 2.3. The $\mathrm{k}$ value difference for the vertical tube sampled oedometer overconsolidated specimen (5.0) is higher than the $\mathrm{k}$ difference for the lathe trimmed oedometer overconsolidated specimen (2.3). This implies that the vertical tube sampled oedometer overconsolidated specimen experienced significantly more disturbance than the lathe trimmed oedometer overconsolidated specimen. This is despite the sample not being extruded from the tube (which may impose some additional disturbance) and the particles touching the border being removed (using the border kill tool, in Avizo)- from the analysis. The stereoplot for the inner and outer sections of the lathetrimmed oedometer specimens are shown in Figures $4 \mathrm{a}$ and $\mathrm{b}$ below.

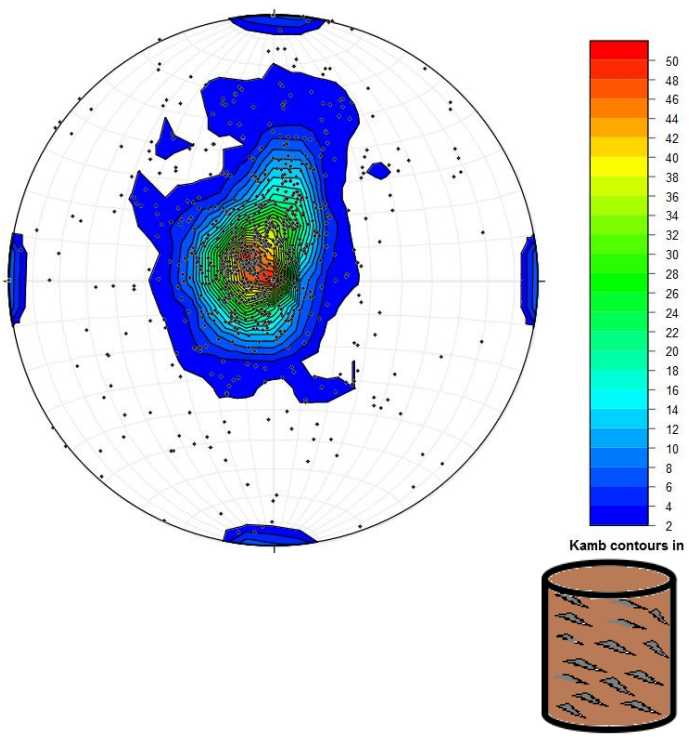

Fig. 4a: Lathe-trimmed oedometer specimen inner section particle pole to planes of the mica particles long axes $(\mathrm{N}=1000)$

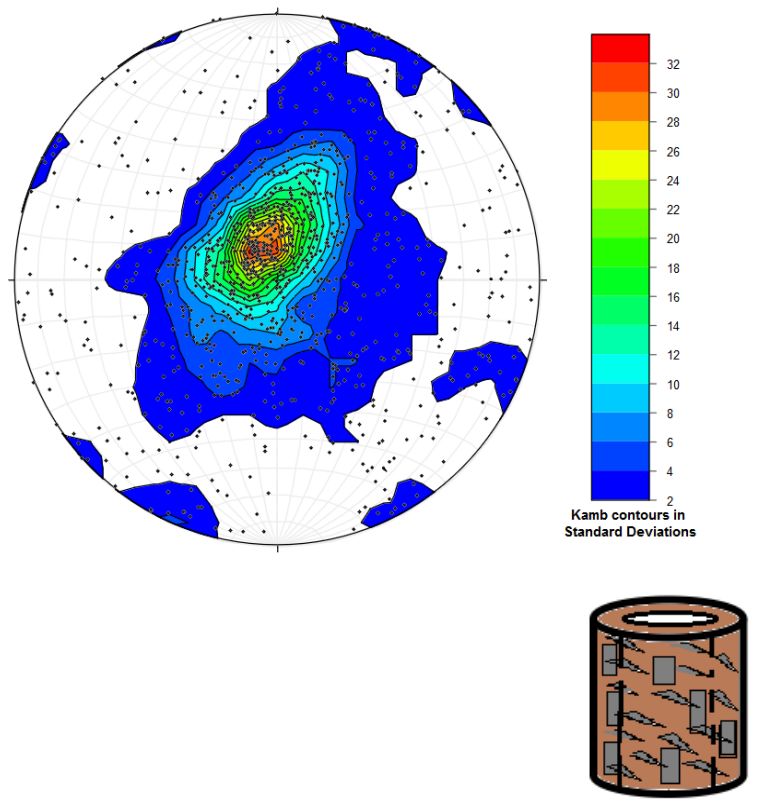

Fig. 4b: Lathe-trimmed oedometer specimen outer section particle pole to planes of the mica particles long axes $(\mathrm{N}=1000)$

Figures $5 \mathrm{a}$ and $\mathrm{b}$ below show a top view of the $\mathrm{X}$-ray $\mathrm{CT}$ images of a typical oedometer consolidated specimen cored with a tube sampler, with the edges showing reoriented mica particles. Figure $5 \mathrm{~b}$ shows the innermost part of the same cored specimen, with the outermost cylindrical section cut off. The outermost part of the original image shows particle alignment (away from the original specimen) to the walls of the tube sampler. The difference is also visible in Figures $5 \mathrm{c}$ and $\mathrm{d}$ (side view of same specimen). 


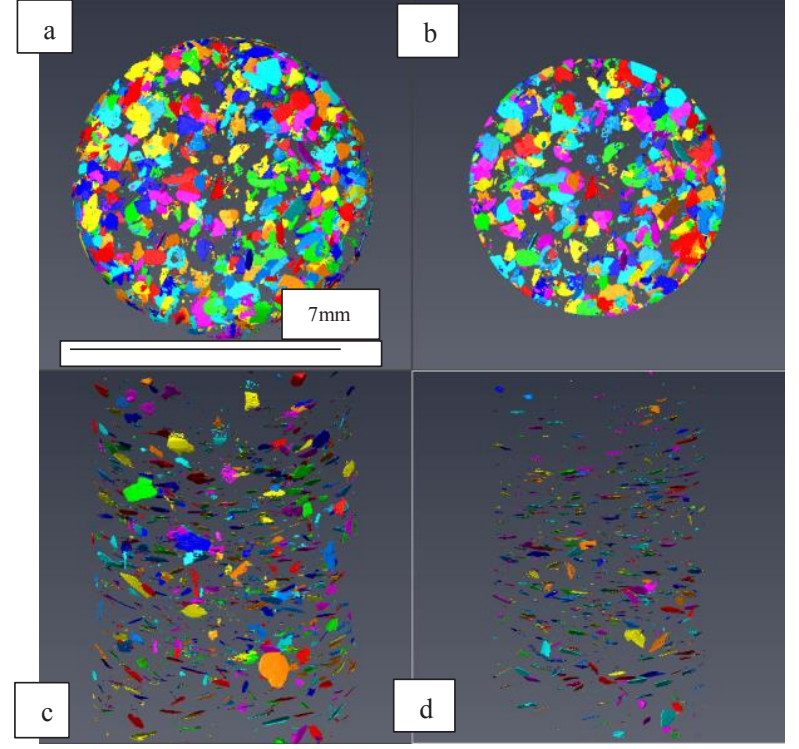

Fig. 5: a) Top view of an oedometer consolidated specimen cored with a tube sampler with the outer surface intact and b) with the outer surface cut off; c) side view of an oedometer consolidated specimen cored with a tube sampler with the outer surface intact and d) with the outer surface cut off.

\subsection{Mould consolidated specimens (to lower stress)}

The vertical and horizontal tube specimen cored from the middle of a cylindrical gypsum mould sample, have $\mathrm{k}$ difference values: 0.2 and 2.4 respectively (Figure 4):

$\left(\left|\mathrm{k}_{\text {inner }}-\mathrm{k}_{\text {outer }}\right|\right.$ horizontal tube mould specimen $)>\left(\left|\mathrm{k}_{\text {inner }}-\mathrm{k}_{\text {outer }}\right|\right.$ vertical tube derived mould specimen)

This implies significantly more disturbance when the specimen was sampled horizontally compared to the specimen sampled vertically. This is actually to be expected, because both the vertical tube sampler and the gypsum mould itself during consolidation, act to orient the particles in alignment with the sides of the mould i.e. vertically. Hence, any sampling disturbance is minimized in the mould prepared sample.

The stereonet representations for the horizontal sampling, which did show significant disturbance, with the gypsum mould are shown in Figures 6a and b.

Significant difference in particle orientation are observed. In the inner section, the undisturbed particles tend to be vertically oriented and there is a significant concentration of particles oriebnted NW-SE on figure 6a, which is perpendicular to te radial direction in which the horizontal sample was taken. This is because during preparation of the sample, the radial suction forces tend to orient the particles parallel to the face through which drainage is occuring. Figure $6 \mathrm{~b}$ shows the orientation of particles within the outer section of the horizontal tube sample. Particles here are now almost entirely randomly oriented and hence are clearly disturbed by the sampling process.

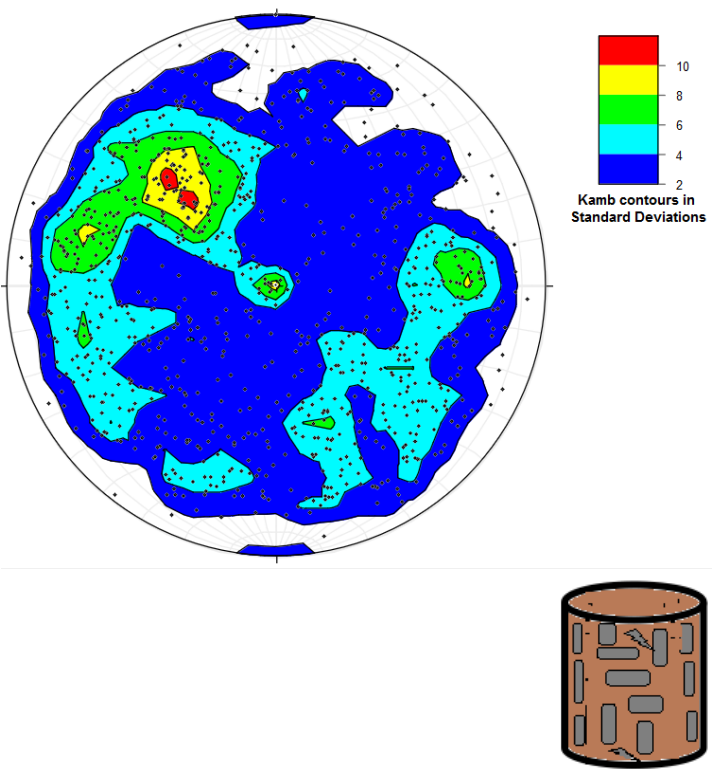

Fig. 6a: Horizontal tube specimen inner section particle pole to planes of the mica particles long axes $(\mathrm{N}=1000)$

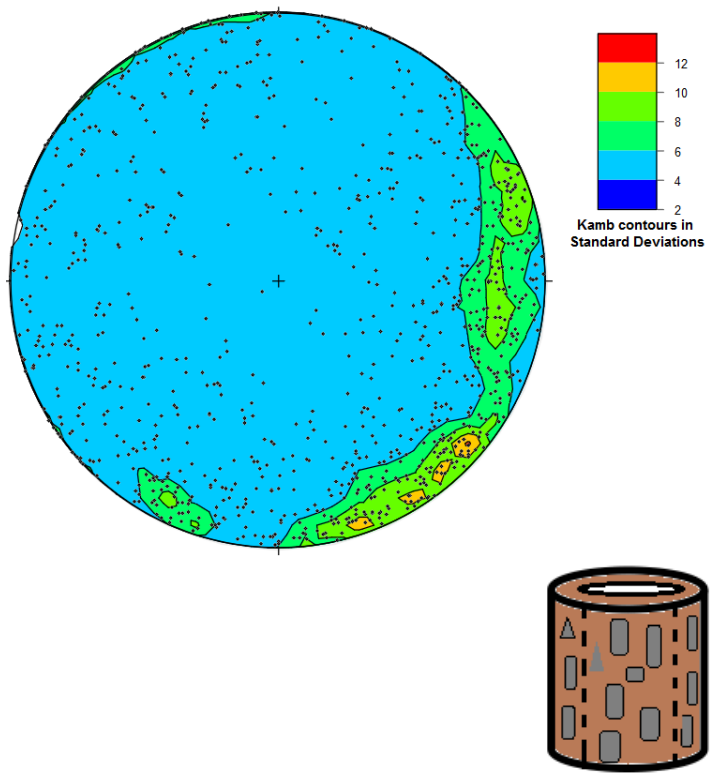

Fig. 6b: Horizontal tube specimen outer section particle pole to planes of the mica particles long axes $(\mathrm{N}=1000)$

\section{Conclusion}

Soil sampling imposes some level of disturbance on soil microstructure and this may affect soil mechanics test results. Miniature cylindrical remoulded kaolin specimens (containing 2\% silt-sand sized mica markers) produced by tube sampling and lathe trimmed sampling were analysed for sample disturbance. Fisher distribution analysis of the mica particle strain markers, represented as poles to planes plotted on stereonets, showed that lathe trimmed vertical specimens may be subject to lesser disturbance when compared to vertical tube sampled specimens for overconsolidated specimens prepared in an oedometer (possibly because tube sampling in addition to the 
limitations of a block trimmed sample is also affected by shear distortion). In the case of gypsum mould prepared samples, the radial suction force results in the particles being preferentially radially-oriented and parallel to the drainage surface. Consequently, vertical tube sampling produced almost no disturbance. We conclude that mica particles can give valuable information on miniature sample disturbance, which can then be mitigated by design of improved sampling methods.

This research is supported by a University of Strathclyde funded $\mathrm{PhD}$ Studentship.

\section{References}

1. A. Emdal, A. Gylland, H.A. Amundsen, K. Kåsin, and M. Long, Mini-block sampler. Canadian Geotechnical Journal, 53(8), 1235-1245 (2016).

2. BS 5930: 1981 - Standard, B., 5930, Code of Practice for Site Investigations. British Standards Institution, London, p.147 (1981)

3. T. Lunne, T. Berre, K.H. Andersen, S. Strandvik, and M. Sjursen, Effects of sample disturbance and consolidation procedures on measured shear strength of soft marine Norwegian clays. Canadian Geotechnical Journal, 43(7), 726-750, (2006)

4. D.J. DeGroot, S.E. Poirier, and M.M. Landon, Sample disturbance-soft clays. Studia Geotechnica et Mechanica, 27(3-4), 91-105 (2005)

5. H.A. Amundsen, V. Thakur, and A. Emdal, Comparison of two sample quality assessment methods applied to oedometer test results. In 6th International Symposium on Deformation Characteristics of Geomaterials. IOS Press, Argentina 923-930 (2015).

6. Avizo Software (2018)

7. R. W. Allmendinger, Stereonet Software (2018)

8. R. W. Allmendinger, N. C. Cardozo, and D. Fisher, Structural ${ }_{\mathrm{p}}$ Geology Algorithms: Vectors \& Tensors: Cambridge, England, Cambridge University Press, 289 (2013)

9. N. Cardozo, and E. W. Allmendinger, Spherical projections with OSXStereonet: Computers \& Geosciences, v. 51, 193 - 205, (2013)

10. N.I. Fisher, T. Lewis, and B. J. Embleton, Statistical analysis of spherical data. Cambridge university press (1993). 